\title{
ОСОБЛИВОСТІ КЛІНІЧНОГО ПЕРЕБІГУ БАЗАЛЬНОПОДІБНОГО РАКУ МОЛОЧНОЇ ЗАЛОЗИ В УМОВАХ ВЕЛИКОГО ПРОМИСЛОВОГО РЕГІОНУ ПІВДЕННОГО СХОДУ УКРАЇНИ
}

\author{
Т. Ю. Погоріла, М. Ф. Щуров \\ Запорізький обласний клінічний онкологічний диспансер

\begin{abstract}
У статті подано результати вивчення деяких особливостей клінічного перебігу базальноподібного раку молочної залози в умовах промислового регіону південного сходу України. Агресивність базальноподібного раку молочної залози та його пізня діагностика призводять до високої ймовірність метастазування та появи рецидивів.
\end{abstract}

Ключові слова: базальноподібний рак молочної залози, маркер.

\section{ОСОБЕННОСТИ КЛИНИЧЕСКОГО ТЕЧЕНИЯ БАЗАЛЬНОПОДОБНОГО РАКА МОЛОЧНОЙ ЖЕЛЕЗЫ В УСЛОВИЯХ ПРОМЫШЛЕННОГО РЕГИОНА ЮГО-ВОСТОКА УКРАИНЫ}

\author{
Т. Ю. Погорелая, Н. Ф. Щуров \\ Запорожский областной клинический онкологический диспансер

\begin{abstract}
В статье представлены результаты изучения некоторых особенностей клинического течения базальноподобного рака молочной железы в условиях большого промышленного региона юго-востока Украины. Агрессивность базальноподобного рака молочной железы и его поздняя диагностика приводят к высокой вероятности метастазирования и появления рецидивов.
\end{abstract}

Ключевые слова: базальноподобный рак молочной железы, маркер.

\section{FEATURES OF CLINICAL COURSE OF BASAL-LIKE BREAST CANCER IN THE CONDITIONS OF LARGE INDUSTRIAL REGION OF SOUTHEAST OF UKRAINE}

\section{Zaporizhzia regional clinical dispansary}

\begin{abstract}
The article presents results of a study of some peculiarities of the clinical course of the basal-like breast cancer in the conditions of large industrial region of southeast of Ukraine. Aggressiveness homeless and late diagnosis leads to its high probability of metastasis and occurrence of relapses.
\end{abstract}

Key words: basal-like breast cancer, marker.

Введение. Рак молочной железы (РМЖ) является наиболее частой причиной смерти женщин по сравнению с другими формами злокачественных новообразований [2, 7].

Рак молочной железы - гетерогенное заболевание, которое различается по морфологическому и молекулярному строению, а также по клиническому течению, и, соответственно, требует различных подходов к диагностике и лечению $[3,4]$.

Термин «базальноподобный» (базалоидный, basal-like), употреблявшийся ранее как сино- ним три-негативного рака молочной железы (ТНРМЖ), не всегда является таковым, что было подтверждено дальнейшими исследованиями [9]. Только $70 \%$ ТНРМЖ являются истинно базальноподобными [8, 12], остальные $30 \%$ - другими фенотипическими вариантами [13]. Вероятность заболеть базальноподобным раком молочной железы (БРМЖ) увеличивается с возрастом $[6,10]$. Вероятность развития базальноподобного рака молочных желез у женщин по возрастам: 46-60 лет - 50,6 \%, 36-45 лет - 24,7\%. 
В результате высокой агрессивности БРМЖ 46,9 \% случаев диагностируется в 3-й стадии, с самой высокой частотой рецидивов $(54,0 \%)$ и частотой метастазирования - в возрастной группе 46-60 лет $(54,6$ \%). Тройной негативный фенотип могут демонстрировать и опухоли с более благоприятным прогнозом - метапластический, аденокистозный, медуллярный рак и другие $[4,12]$. Около $5 \%$ БРМЖ экспрессируют ER и PR, а 6-12 \% - HER2/ neu $[1,3]$. Если учесть определенную частоту ложноотрицательных результатов при иммуногистохимическом определении стероидных рецепторов, то следует признать, что ТН-фенотип является суррогатным (и не идеальным) маркером, который может использоваться для идентификации БРМЖ с известной долей условности $[11,12]$. Проблема поиска более надежных маркеров БРМЖ остается актуальной для исследователей [2, 12].

Цель работы: показать особенности клинического течения базальноподобного рака молочной железы в условиях большого промышленного региона юго-востока Украины.

Материалы и методы исследования. Проводились исследования у 81 пациентки в возрасте 29-73 лет, которые проходили лечение в соответствии с клиническими протоколами лечения РМЖ

в Запорожском областном клиническом онкологическом диспансере в 2008-2012 гг. У всех пациенток оценивали: стадию заболевания, возраст на момент постановки диагноза, размер, гистологический тип и степень дифференцировки опухоли, а также наличие метастазов и рецидивов.

Материал для гистологического исследования был получен во время оперативного вмешательства. Для обработки результатов исследования использовали программу MS Excel [1]. Статистически достоверными считали различия между показателями при уровне значимости $\mathrm{p}<0,05$.

Результаты и их обсуждение. У всех пациенток диагностировали базальноподобный рак молочной железы на основании иммуногистохимического метода (табл. 1).

Как видно из табл.1, наибольшее количество больных в возрастной группе 46-60 лет - 41 человек, далее следует возрастная группа 36-45 20 человек, далее свыше 61 года - 17 и наименьшее количество заболевших в возрасте 20-35 лет 3 человека.

Нами были проведены исследования частоты выявления БРМЖ в зависимости от стадии. Результаты представлены в табл. 2.

Обнаружено, что среди больных БРМЖ на-

Таблиича 1

Распределение больных базальноподобным раком молочной железы по возрасту $($ р<0,05)

\begin{tabular}{|c|c|c|c|c|c|c|c|c|c|c|}
\hline \multirow{3}{*}{ Группа } & \multicolumn{8}{|c|}{ Возраст } & \multirow{2}{*}{\multicolumn{2}{|c|}{ Всего }} \\
\hline & \multicolumn{2}{|c|}{$20-35$} & \multicolumn{2}{|c|}{$36-45$} & \multicolumn{2}{|c|}{$46-60$} & \multicolumn{2}{|c|}{ от 61} & & \\
\hline & абс. & $\%$ & абс. & $\%$ & абс. & $\%$ & абс. & $\%$ & абс. & $\%$ \\
\hline Основная & 3 & 3,7 & 20 & 24,7 & 41 & 50,6 & 17 & 21,0 & 81 & 100 \\
\hline
\end{tabular}

Таблицуа 2

Распределение больных базальноподобным раком молочной железы по стадиям (р<0,05)

\begin{tabular}{|c|c|c|c|c|c|c|c|c|c|c|}
\hline \multirow{3}{*}{ Группа } & \multicolumn{8}{|c|}{ Стадия } & \multirow{2}{*}{\multicolumn{2}{|c|}{ Всего }} \\
\hline & \multicolumn{2}{|c|}{1} & \multicolumn{2}{|c|}{2} & \multicolumn{2}{|c|}{3} & \multicolumn{2}{|c|}{4 я } & & \\
\hline & абс. & $\%$ & абс. & $\%$ & абс. & $\%$ & абс. & $\%$ & абс. & $\%$ \\
\hline Основная & 18 & 22,2 & 17 & 21,0 & 38 & 46,9 & 8 & 9,9 & 81 & 100,0 \\
\hline
\end{tabular}

Таблица 3

Частота рецидивов у больных базальноподобным раком молочной железы в зависимости от стадии $(\mathbf{p}<0,05)$

\begin{tabular}{|c|c|c|c|c|c|c|c|c|c|c|}
\hline \multirow{3}{*}{ Показатель } & \multicolumn{8}{|c|}{ Стадия } & \multirow{2}{*}{\multicolumn{2}{|c|}{ Всего }} \\
\hline & \multicolumn{2}{|c|}{1} & \multicolumn{2}{|c|}{2} & \multicolumn{2}{|c|}{3} & \multicolumn{2}{|c|}{4} & & \\
\hline & абс. & $\%$ & абс. & $\%$ & абс. & $\%$ & абс. & $\%$ & абс. & $\%$ \\
\hline Основная группа & 18 & 22,2 & 17 & 21,0 & 38 & 46,9 & 8 & 9,9 & 81 & 100,0 \\
\hline $\begin{array}{c}\text { Частота } \\
\text { рецидивов }\end{array}$ & 3 & 10,7 & 4 & 14,3 & 15 & 54,0 & 6 & 21,0 & 28 & 100,0 \\
\hline
\end{tabular}




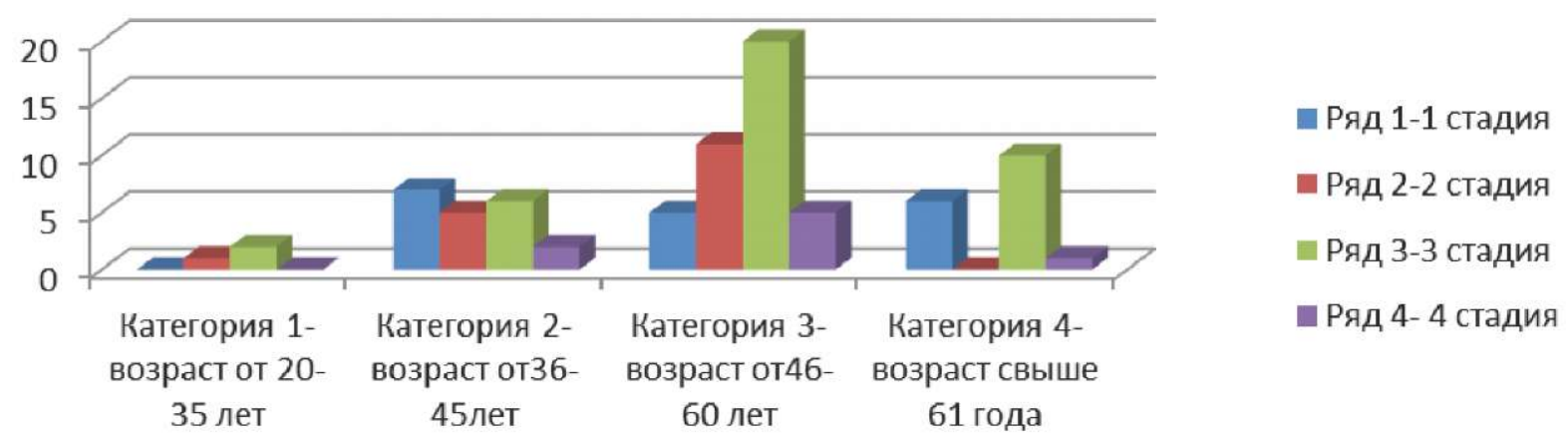

Рис. 1. Распределение больных базальноподобным раком молочной железы по стадиям и возрасту

ибольшее число больных с 3 -й стадией развития опухолевого процесса - 38 человек, потом 1 и 2 стадия - соответственно 18 и 17 человек, а рак 4-й стадии выявлен у 8 больных.

Взаимосвязь возраста и стадии заболевания представлены на рис. 1.

Из рис. 1 видно, что во всех возрастных группах, кроме 36-45 лет, преобладает 3 стадия заболевания.

Следующим исследуемым показателем была зависимость частоты рецидивов БРМЖ от стадии (табл. 3).

Как видно из табл. 3, на 3 -ю стадию приходится наибольшее число рецидивов - 15 , что составляет
54 \% всех рецидивов. На втором месте по количеству рецидивов находится 4-я стадия - 6 случаев. У больных со 2 стадией обнаружено 4 рецидива, a с 1 стадией всего 3 случая.

Далее нами была определена зависимость частоты рецидивов БРМЖ от возраста (табл. 4).

По результатам табл. 4 видим, что на 3 возрастную группу приходится наибольшее число рецидивов - 15 , далее по количеству рецидивов группа больных с возрастом выше 61 года 9 случаев, у больных возрастной группы 36-45лет - обнаружено 3 рецидива, а у больных 20-35 лет - 1 случай.

Таблицุа 4

\section{Частота рецидивов у больных базальноподобным раком молочной железы в зависимости от возраста $(\mathbf{p}<0,05)$}

\begin{tabular}{|c|c|c|c|c|c|c|c|c|c|c|}
\hline \multirow{3}{*}{ Группа } & \multicolumn{8}{|c|}{ Возраст } & \multirow{2}{*}{\multicolumn{2}{|c|}{ Всего }} \\
\hline & \multicolumn{2}{|c|}{$20-35$} & \multicolumn{2}{|c|}{$36-45$} & \multicolumn{2}{|c|}{$46-60$} & \multicolumn{2}{|c|}{ от 61} & & \\
\hline & абс. & $\%$ & абс. & $\%$ & абс. & $\%$ & абс. & $\%$ & абс. & $\%$ \\
\hline Основная & 1 & 3,6 & 3 & 10,7 & 15 & 53,6 & 9 & 32,1 & 28 & 100,0 \\
\hline
\end{tabular}

Таблицуа 5

Частота метастазирования у больных базальноподобным раком молочной железы в зависимости от стадии $(\mathbf{p}<0,05)$

\begin{tabular}{|c|c|c|c|c|c|c|c|c|c|c|}
\hline \multirow{3}{*}{ Показатель } & \multicolumn{8}{|c|}{ Стадия } & \multirow{2}{*}{\multicolumn{2}{|c|}{ Всего }} \\
\hline & \multicolumn{2}{|c|}{1 стадия } & \multicolumn{2}{|c|}{2 стадия } & \multicolumn{2}{|c|}{3 стадия } & \multicolumn{2}{|c|}{4 стадия } & & \\
\hline & абс. & $\%$ & aбc. & $\%$ & абс. & $\%$ & абс. & $\%$ & абс. & $\%$ \\
\hline Основная & 18 & 22,2 & 17 & 21,0 & 38 & 46,9 & 8 & 9,9 & 81 & 100,0 \\
\hline Частота Mts & - & - & - & - & 14 & 63,6 & 8 & 36,4 & 22 & 100,0 \\
\hline
\end{tabular}

Таблицьа 6

Частота метастазирования у больных базальноподобным раком молочной железы в зависимости от возраста $(\mathbf{p}<0,05)$

\begin{tabular}{|c|c|c|c|c|c|c|c|c|c|c|}
\hline \multirow{3}{*}{$\begin{array}{c}\text { Основная } \\
\text { группа }\end{array}$} & \multicolumn{8}{|c|}{ Возраст } & \multirow{2}{*}{\multicolumn{2}{|c|}{ Всего }} \\
\hline & \multicolumn{2}{|c|}{$20-35$} & \multicolumn{2}{|c|}{$36-45$} & \multicolumn{2}{|c|}{$46-60$} & \multicolumn{2}{|c|}{ от 61} & & \\
\hline & абс. & $\%$ & абс. & $\%$ & абс. & $\%$ & абс. & $\%$ & абс. & $\%$ \\
\hline Частота Mts & 2 & 9,1 & 3 & 13,6 & 12 & 54,6 & 5 & 22,7 & 22 & 100,0 \\
\hline
\end{tabular}


Завершали исследование сравнением частоты метастазирования у больных БРМЖ в зависимости от стадии (табл. 5) и в зависимости от возраста (табл. 6).

Установлено, что самое большое количество Mts встречается у больных с 3 стадией развития опухолевого процесса - 14, а у больных с 4 стадией - 8 случаев.

Показано (табл. 6), что на возрастную группу 46-60 приходится наибольшее число метастазов - 12, далее следует группа больных с возрастом больше 60 лет - 5 случаев, в возрастной группе 36-45 лет - обнаружено 3 метастаза, а у больных в группе 20-35 лет - 2 случая.

Выводы. 1. Наибольшее количество Mts встречается у больных с 3 стадией развития опухолевого процесса - 63,6\%.

2. Вероятность заболеть базальноподобным раком молочной железы увеличивается с возрастом. Вероятность развития базальноподобного рака молочных желез у женщин 46-60 лет - 50,6 \%, далее следует возрастная группа 36-45 лет - 24,7 \%.

3. В результате высокой агрессивности диагностируется БРМЖ в 46,9 \% случаях в 3 стадии, с самой высокой частотой рецидивов - 54,0\% и частотой метастазирования в возрастной группе 46-60 лет - 54,6 \%.

4. В возрастной группе больных 46-60 лет также встречается наибольшее число метастазов - 12, что составляет 54,6 \% всех рецидивов.

Авторы исследования обращают внимание на актуальность тематики работы и необходимость более глубокого исследования. В результате высокой агрессивности крайне важно диагностировать БРМЖ на ранних стадиях, особенно в условиях большого промышленного региона. Также оценка определенных особенностей клинического течения базальноподобного рака молочной железы нужна для более точного индивидуального подбора комплексного лечения.

\section{Литература.}

1. Статистика в науке и бизнесе / Лапач С. Н., Чубенко А. В., Бабич П. Н. - К. : МОРИОН, 2002. - С. $195-207$.

2. Факторы риска развития местных рецидивов инвазивного рака грудной железы / Щепотин И. Б., Зотов А. С., Любота И. И. и др. // Онкология. - 2010.- 4(12) - С. 347-350.

3. Claudin-1 and -2 : novel integral membrane proteins localizing at tight junctions with no sequence similarity to occluding / Furuse M., Fujita K., Hiiragi T. et al. // J. Cell Biol. - 1998. - 7 (141). - P. 1539-1550.

4. Prevalence of BRCA1 mutations in triple negative breast cancer (BC) / Kandel M. J., Stadler Z., Masciari S. et al. // J. Clin. Oncol. - 2006. - P. 508.

5. Molecular portraits of human breast tumours / Perou C. M., Sorlie T., Eisen M. B. et al. // Nature. - 2000. - 406. P. 747-752.

6. Mammary development meets cancer genomics / Prat A., Perou C. M. // Nat Med., 2009. - 15. - P. 842-844.

7. Breast cancer molecular subtypes respond differently to preoperative chemotherapy / Rouzier R., Perou C., SymmansW. et al. // Clin. Cancer Res. - 2005. - P. 85.

8. Gene expression patterns of breast carcinomas distinguish tumor subclasses with clinical implications / Sorlie T., Perou C. M., Tibshirani R. et al. // Proc Natl Acad Sci USA. - 2001. - 98. - P. 10869-10874.

9. Repeated observation of breast tumor subtypes in independent gene expression data sets / Sorlie T., Tibshirani R., Parker J. et al. // Proc Natl Acad Sci USA. - 2003. - 100. - P. 8418-8423.

10. Breast cancer classification and prognosis based on gene expression profiles from a population based study / Sotiriou C., Neo S. Y., McShane L. M. et al. // Proc Natl Acad Sci USA. - 2003. - 100. - P. 10393-10398.

11. Molecular classification of breast carcinomas by immunohistochemical analysis / Tang P., Skinner K. A., Hicks D. G. // Diagn Mol Pathol. - 2009. - P. 125-132.

12. Use of immunohistochemical markers can refine prognosis in triple negative breast cancer / Tischkowitz M., Brunet J. S., Begin L.R. et al. // BMC Cancer. - 2007. - P. 134.

13. The other triple-negative breast cancer: Immunohistochemical and clinicopathologic characterization of the claudin-low subtype / Voduc D., Cheang M. C., Prat A. et al. // J Clin Oncol. - 2011. - P. 29.

14. The prevalence of BRCA mutations among young women with triple-negative breast cancer/Young S., Pilarski R., Donenberg T. et al. // BMC Cancer. -2009. - 1(9). - P. 86-91. 